\title{
Factores que limitan el potencial de rendimiento del maíz de polinización abierta en campos de pequeños productores de la Sierra de Ecuador
}

\author{
Factors affecting yield potential of open pollinated corn in \\ small farmers' fields in the Ecuadorian highlands
}

\author{
Roberto Boada ${ }^{1}$, José Espinosa ${ }^{1}$ \\ ${ }^{1}$ Universidad Central del Ecuador. Facultad de Ciencias Agricolas. Instituto de Investigación y Posgrado. \\ Jerónimo Leiton y Av. La Gasca s/n. Ciudadela Universitaria. Quito. 170521. Ecuador.
}

\section{Resumen}

Esta revisión bibliográfica describe, desde el estricto punto de vista agronómico, la situación actual de la producción de maíz de polinización abierta en manos de productores de agricultura familiar en la Sierra de Ecuador y basándose en lo encontrado propone tareas de investigación que podrían mejorarla. La discusión no considera las obvias condiciones socio-económicas que afectan también a este sistema de producción. La producción de maíz suave de polinización abierta para grano seco y choclo es una opción interesante dentro de los cultivos que los productores de agricultura familiar utilizan para su sustento y para la generación de ingresos a su economía. Sin embargo, las técnicas tradicionales para producción de maíz como la preparación del suelo y la siembra no logran que el cultivo se desarrolle adecuadamente y produzca el potencial de rendimiento que el ambiente permite. Se pueden lograr poblaciones altas y uniformes utilizando cuidadosamente el espeque y colocando una sola semilla por sitio a distanciamientos que pueden variar de 0,7 a $0,8 \mathrm{~m}$ entre hileras y de 0,18 a 0,25 m entre plantas para lograr densidades de siembra superiores a 60000 plantas ha ${ }^{-1}$. De esta forma, las plantas crecen uniformemente, pueden utilizar la luz de manera adecuada y pueden acumular rendimientos de grano adecuados. Si el objetivo es producir choclo, esta forma de siembra asegura una mazorca de adecuado tamaño por planta que permite producir buen choclo para el mercado. Por otro lado, es necesario reducir o eliminar el movimiento del suelo para tareas de siembra y control de malezas por medio de siembra directa. Esta forma de manejo no remueve el suelo, deja que se acumulen los residuos de cosechas anteriores en la superficie y coloca la semilla en el suelo sin moverlo. Esta es quizá la práctica de manejo de suelo que tendría más impacto a largo plazo en la producción ya que permite que los suelos se recuperen al mejorarse sus propiedades físicas, químicas y biológicas y al lograr acumular carbono orgánico en el suelo.

Palabras clave: agricultura familiar, maíz suave, siembra directa.

\begin{abstract}
This literature review describes, from the strict agronomic view point, the actual production situation of the open pollinated corn varieties in the hands of familiar agriculture producers in the Ecuadorian highlands and based on the findings suggests research tasks that could improve it. The discussion does not consider the obvious socio-economic conditions that also affect this production system. The production of soft open pollinated corn varieties for grain and corn in the cob is an interesting option among the crops for familiar agriculture
\end{abstract}


which farmers use for self-consumption and to generate household income. However, the traditional techniques utilized for corn production like soil preparation and seeding are not conductive to obtain the growth and potential yield that the environment allows. It's possible to achieve high uniform plant population using the seeding stick carefully and placing one seed at each planting hill at spaces that can vary from 0.7 to $0.8 \mathrm{~m}$ between plant rows and 0.18 to $0.25 \mathrm{~m}$ Between plants to obtain plant densities greater than 60000 plants ha $^{-1}$. This way, plants grow uniformly, utilize light efficiently and can accumulate adequate grain yield. If the objective is to produce corn in the cob, this planting procedure ensures a quantity of good size cobs for the market. On the other hand, it's compulsory to reduce or eliminate soil movement for planting and weed control tasks by means of no-till. This management practice does not remove the soil, let plant residue accumulate on the surface and seed placement does not disturb the soil. This is perhaps the management practice which will have the most impact in corn production in the long term because it allows soil physical, chemical and biological properties recuperation and accumulates organic carbon in the soil.

Keywords: familiar agriculture, soft corn, no-till.

\section{Introducción}

Los cambios en la estructura de la tenencia de la tierra de los últimos 60 años han promovido el desarrollo de un gran grupo de propietarios de predios pequeños que se mantienen de lo que hoy se conoce como agricultura familiar. Este modelo mantiene su coherencia productiva por el uso de la fuerza familiar de trabajo y contribuye con diferentes productos a mantener la seguridad alimentaria del país. Uno de estos productos es el maíz suave de polinización abierta que en el año 2009 contribuyó con 23,5 millones de dólares a la economía nacional. La producción de maíz suave en el país se encuentra en la mayoría de provincias de la Sierra, se distribuye en altitudes entre 2.000-3.000 msnm y es utilizado como choclo (mazorca tierna) y en diferentes formas como grano seco. La producción promedio de grano del país es baja $\left(\approx 1 \mathrm{tha}^{-1}\right)$ uno de los rendimientos más bajos de Sudamérica. Los bajos rendimientos son consecuencia de varios factores, entre los que se destacan la utilización de material genético no apropiado, siembra tradicional que lleva a poblaciones bajas y poco uniformes en el campo y movimiento continuo del suelo para las labores de preparación del suelo para la siembra y control de malezas. Esta revisión bibliográfica busca identificar los principales problemas de la producción de maíz suave de polinización abierta en los lotes de productores de agricultura familiar en la Sierra de Ecuador y con esta información esbozar sugerencias para mejorar el manejo del suelo y el cultivo buscando incrementar los rendimientos de este rublo importante en la economía de la agricultura familiar. La discusión no considera las obvias condiciones socio-económicas que afectan también a este sistema de producción.

\section{Situación de la tenencia de la tierra de pequeños productores de la Sierra ecuatoriana}

Ecuador es un país pequeño que posee una superficie de $256370 \mathrm{~km}^{2}$, el 47\% de los cuales está ubicado en la Región Amazónica, 25\% en la Costa, 24\% en la Sierra y $3 \%$ en Galápagos. El país es megadiverso y concentra una gran variedad de plantas y animales en una superficie relativamente pequeña (Vásquez \& Saltos, 2000). Una breve descripción de los procesos de la tenencia de la tierra en Ecuador podría empezar indicando que después de la independencia los grandes poseedores de tierra no permitieron que se formularan normativas que pudieran afectar la tenencia de los latifundios quedando la situación de posesión en las mismas condiciones que existieron en la Colonia. Solamente en 1908, en medio del movimiento liberal de Alfaro, se hace el primer intento de cambio en la tenencia de la tierra con la promulgación de la Ley de Beneficencia que finalmente afecta los latifundios de las órdenes religiosas. Sin embargo, cuando empieza la década de 1960, la acción de varios movimientos sociales desde el sector campesino, que buscan acceso a la tierra, y desde el mismo sector terrateniente, que busca modernizar la actividad agrícola, hacen que el Estado contemple la posibilidad de formular una ley que reestructure la situación de tenencia de la tierra en Ecuador. Bajo esta presión, en 1964 el Estado promulga la Ley de Reforma Agraria y Colonización basán- 
dose en los principios propuestos por la reunión de la OEA en Punta del Este, Uruguay, en 1961, principios que son muy parecidos a los que proponía el programa denominado Alianza para el Progreso, promovido por el gobierno de los Estados Unidos, como solución para los problemas de tierra de América Latina. La nueva ley plantea, entre sus puntos principales, eliminar las formas precarias de producción (mano de obra gratuita) conocidas como huasipungo, parcelar las haciendas del Estado y pasarlas a manos de los campesinos e impulsar el proceso de incorporación de nuevas tierra a la actividad agrícola por medio de la colonización (Brassel et al., 2008).

Los mismos autores indican que en ese momento el efecto principal de la promulgación de la ley sería el de suavizar la acción de los movimientos sociales, al mismo tiempo que promovía la modernización de la actividad agrícola, pero la denominada lucha por la tierra solamente se dinamizó y en este periodo de tiempo donde aparecen organizaciones campesina como la Federación Nacional de Organizaciones Campesinas (FENOC) y la Ecuador Runacunapac Riccharimui (ECUARUNARI) que propusieron una agenda muy activa bajo el lema de "tierra para quien la trabaja. Por otro lado, desde el Estado se consideraba que la reforma agraria no solo debía satisfacer la necesidad de justicia social, sino que fundamentalmente debía ser una de las columnas que sostenga el proceso de industrialización del país para substituir las importaciones. Se consideraba que la reforma agraria mejoraría los ingresos campesinos y que los haría consumidores de productos industrializados y que de esta forma se potenciaría la producción del agro presionando a los medianos y grandes productores a transformarse en empresarios agrícolas. Esta concepción es la que se plasma en la nueva Ley de reforma Agraria promulgada en 1973 por el gobierno de Rodríguez Lara.

La presión sobre la tenencia de la tierra continuó durante la década de 1970 por parte de los campesinos, pero particularmente por parte de los latifundistas que consideraban que las leyes promulgadas atentaban contra sus intereses porque la consideraban de carácter confiscatorio. En 1979, la presión de los latifundistas promueve la aprobación de la Ley de Fomento y Desarrollo Agropecuario que garantizaba la seguridad de la tierra que fuese eficientemente trabajada con el espíritu de promover el desarrollo empresarial de medianos y grandes productores. Esta nueva ley no satisfizo las aspira- ciones de los terratenientes que sugirieron cambios a la normativa que se plasmaron en la Ley de Desarrollo Agrario aprobada en 1994 por el gobierno de Sixto Durán Ballén. Esta nueva ley agraria deroga las normativas de la Ley de Reforma Agraria eliminando las restricciones a la venta de las propiedades rurales, y la tenencia de la mediana. Gran propiedad pasa a estar garantizada por el Estado y permite que las tierras comunales puedan fraccionarse y venderse (Brassel et al., 2008).

Analizando las secuelas de las leyes que afectaron la tenencia de la tierra en Ecuador se puede concluir diciendo que éstas transformaron las grandes haciendas en unidades de producción de modelo capitalista, pero, por otro lado, promovieron también el acceso a la tierra de un alto número de personas, situación que derivó en el desarrollo de extensas áreas de tierra bajo minifundio. Los datos estadísticos del periodo de 1964 a 1994 indican que la superficie total intervenida por la Reforma Agraria fue de 9.026 $\mathrm{km}^{2}(\approx 900.000 \mathrm{ha})$, el $3,4 \%$ de la superficie total del país. Esta superficie es baja si se compara con el efecto de la colonización, promovida también por la Ley de Reforma Agraria, que incorporó $63.631 \mathrm{~km}^{2}$ a las actividades agrícolas (6,36 millones de has), es decir, el 23\% del territorio nacional (Gondard y Mazurek, 2001). A pesar de estos cambios, la estructura básica de la tenencia de la tierra no ha variado significativamente en los últimos 50 años como lo demuestran los datos de los censos de 1954, 1974 y 2000 presentados en el Cuadro 1. Estos datos indican que ha existido un incremento de $138 \%$ en el número de predios y que la superficie agrícola se ha expandido en $106 \%$, sin embargo, estos cambios no han afectado en forma importante la tenencia de la tierra, caracterizada por mucha tierra en manos de grandes propietarios. En efecto, los datos del censo agropecuario de 1954 indican que el 71,1\% de las Unidades de Producción Agropecuaria (UPA) con menos de 5 ha cubrían solamente el 7,2\% de la superficie cultivada y que las propiedades con más de 100 ha cubrían el $64,4 \%$ de la superficie del territorio nacional ocupado por las UPA. A pesar del incremento significativo en la superficie del territorio nacional bajo uso agropecuario (5'999.700 hectáreas en 1954 a 12'355.830 en el año 2000), en general, la situación en el año 2000 es bastante parecida en términos porcentuales al año 1954, las propiedades con menos de 5 ha representaban el $63,5 \%$ del total de UPA, pero ocupaban solamente el $6,3 \%$ de la tierra bajo uso agropecuario, mientras que las UPA de más 
de 100 ha representaban solo el 2,3\%, pero ocupaban el $42,6 \%$ de la tierra bajo uso agropecuario (Brassel et al., 2008; Carrión \& Herrera, 2012).

Como consecuencia de la estructura de la tenencia de la tierra desarrollada en los últimos 60 años se ha proyectado en la economía nacional un gran grupo de propietarios de predios pequeños que han generado un sector de la economía denominado agricultura familiar, asociada a términos como agricultura campesina, pequeña agricultura o agricultura de subsistencia. Este modelo mantiene su racionalidad productiva asociada al uso de la fuerza familiar de trabajo, pero no se sostiene en el tiempo exclusivamente de lo generado por la producción agrícola sino que depende de los ingresos obtenidos fuera de la finca en prestación de mano de obra en propiedades grandes o en los servicios. A pesar de las restric- ciones que ofrece el modelo, la agricultura campesina no solo que produce para el autoconsumo, sino que además produce para cubrir las necesidades del mercado interno y es un motor para la conservación de la agrodiversidad y es una herramienta importante para revitalizar la economía, luchar contra pobreza y sentar bases para construir una sociedad más equitativa (Berry \& North, 2011; Carrión \& Herrera, 2012). Esta es la denominada economía familiar campesina (EFC) cuya contribución por productos típicamente campesinos al valor agregado de la economía nacional en el año 2009 fue la siguiente: maíz duro seco 43 millones de dólares, yuca 25 millones, maíz suave seco 23,5 millones, cacao 23 millones, fréjol seco 15,5 millones y maíz suave choclo $11 \mathrm{mi}$ llones (Carrión y Herrera, 2012). Se nota entonces que el maíz suave producido en la Sierra ecuatoriana representa un rublo interesante para la EFC.

Cuadro 1. Descripción de la tenencia de la tierra según los censos de 1954, 1975 y 2000 (adaptado de Brassel et al., 2008).

\begin{tabular}{|c|c|c|c|c|c|c|}
\hline \multirow[t]{2}{*}{ UPA's } & \multicolumn{3}{|c|}{ Número de propiedades } & \multicolumn{3}{|c|}{ Porcentaje del total de propiedades } \\
\hline & Censo 1954 & Censo 1975 & Censo 2000 & Censo 1954 & Censo 1975 & Censo 2000 \\
\hline \multicolumn{7}{|c|}{ 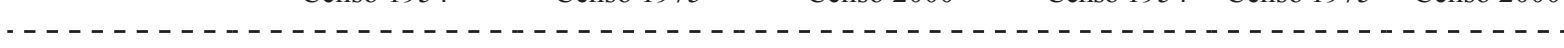 } \\
\hline$<5$ ha & 251.686 & 346.877 & 535.309 & 71,1 & 66,8 & 63,5 \\
\hline $5-20$ ha & 67.650 & 96.360 & 176.726 & 19,1 & 18,6 & 21,0 \\
\hline $20-100$ ha & 27.742 & 64.813 & 111.290 & 7,8 & 12,5 & 13,2 \\
\hline$>100$ ha & 71.56 & 11.091 & 19.557 & 2,0 & 2,1 & 2,3 \\
\hline Total ha & 354.234 & 519.141 & 842.882 & 100 & 100 & 100 \\
\hline \multicolumn{7}{|c|}{ - - - - - - - - - - - - - - - - - - - - - - - - - - - - - - - - - - - - - - - - - - - - - - - } \\
\hline & \multicolumn{3}{|c|}{ Superficie en hectáreas } & \multicolumn{3}{|c|}{ Porcentaje de la superficie total } \\
\hline \multicolumn{7}{|c|}{ 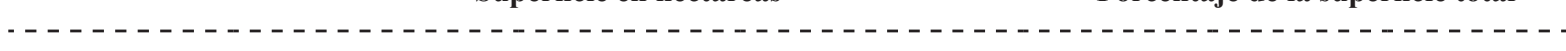 } \\
\hline$<5$ ha & 432.220 & 538.700 & 774.225 & 7,2 & 6,8 & 6,3 \\
\hline $5-20$ ha & 565.800 & 935.300 & $1^{\prime} 706.794$ & 9,4 & 11,8 & 13,8 \\
\hline $20-100$ ha & 1'138.700 & $2^{\prime} 664.700$ & $4^{\prime} 614.436$ & 19,0 & 33,5 & 37,3 \\
\hline$>100 \mathrm{ha}$ & 3'863.000 & 3'810.800 & $5 ’ 260.375$ & 64,4 & 47,9 & 42,6 \\
\hline Total ha & $5^{\prime} 999.700$ & $7^{\prime} 949.500$ & $12^{\prime} 355.830$ & 100 & 100 & 100 \\
\hline
\end{tabular}

\section{La producción de maíz suave en el Ecuador}

\subsection{Maices de polinización abierta}

El 44\% de la producción de maíz en el mundo se realiza con híbridos, el 14\% con variedades de po- linización libre mejoradas y el $42 \%$ con variedades de polinización abierta no mejoradas. Las variedades de polinización abierta se utilizan principalmente en los países en desarrollo fundamentalmente para alimentación humana. En general, el maíz de polinización abierta se siembra, dependiendo de la latitud, desde los 
1600 hasta los 3000 m. s. n. m., mientras que el maíz híbrido se utiliza en las regiones tropicales de América (Pandey et al., 1986). Los mismos autores indican que las variedades de maíz de polinización abierta se logran a partir de las razas nativas, se clasifican en compuestas y sintéticas, son fáciles de desarrollar y mantener, su producción es simple y más económica y permite que los agricultores pequeños conserven su propia semilla para mantener los ciclos de siembra. En la producción de semillas de polinización abierta solo participa un progenitor en la multiplicación de los materiales.

El enfoque para la conservación de variedades locales de maíz de polinización abierta de América Latina se basa en dos criterios: 1) adaptación a determinados nichos ecológicos y 2) formas especiales de consumo de variedades específicas. La utilización de germoplasma nativo varía en función del país y las necesidades de desarrollo. En general, la estrategia consiste en identificar las fuentes de germoplasma élite por medio de la caracterización y evaluación de muestras de colecciones autóctonas. Los programas nacionales e internacionales, las industrias privadas de semillas y las universidades utilizan este germoplasma para sus programas de mejoramiento. Sin embargo, todavía hay mucho germoplasma en los campos agrícolas que no ha sido evaluado para entrar en programas de mejoramiento que permitan generar materiales estables y de buenas características para uso de los productores (Márquez Sánchez, 2008).

\subsection{Maíz suave de polinización abierta en Ecuador}

En Ecuador se encuentran diecisiete razas de maíces suaves de polinización abierta distribuidas en la Sierra en tres grandes zonas: 1) Zona norte que comprende las provincias de Carchi, Imbabura, Pichincha y Cotopaxi y que produce maíces amarillos harinosos como Caucho, Huandango, Mishca y Chillos; 2) Zona central ubicada en las provincias de Tungurahua, Chimborazo y Bolívar y donde se producen maíces de grano blanco harinoso de las razas Blanco Blandito y Cuzco Ecuatoriano; y, 3) Zona sur que comprende las provincias de Azuay, Cañar y Loja y que cultiva variedades de tipo Zhima. En todas las zonas se encuentra también morocho blanco (Yanez et al., 2003). La distribución de las diferentes variedades de maíz, a más de estar determinadas por las preferencias del agricultor, también se cultivan dependiendo del gusto del consumidor, se destaca el maíz amiláceo consumido intensamente por la población rural ya que a más de su valor nutritivo contribuye a la economía de la agricultura campesina (INIAP, 2008; Peñaherrera, 2011). Al momento, las variedades de maíz suave adaptadas a condiciones especiales de altitud son ampliamente difundidas en la Sierra ecuatoriana y se caracterizan por la duración del ciclo productivo en precoces o tardías. Las variedades de maíz suave desarrolladas y liberadas por INIAP se presentan en el Cuadro 2 a continuación.

Cuadro 2. Distribución y zonas de adaptación de las variedades de maíz de polinización abierta liberadas por INIAP (adaptado de INIAP, 2008).

\begin{tabular}{|c|c|c|c|c|}
\hline Variedad & Tipo & Duración ciclo & Altitud & Zona \\
\hline & & (días promedio) & (m s.n.m.) & \\
\hline $\begin{array}{c}\text { INIAP } 101 \\
\text { Blanco harinoso }\end{array}$ & Precoz & 205 & $2400-3000$ & Azuay y Cañar \\
\hline INIAP 102 & Tardía & 270 & $2200-2800$ & Chimborazo \\
\hline $\begin{array}{c}\text { INIAP } 111 \\
\text { Blanco harinoso }\end{array}$ & Tardía & 270 & $2400-2800$ & Bolívar \\
\hline $\begin{array}{c}\text { INIAP } 122 \\
\text { Amarillo harinoso }\end{array}$ & Semi precoz & 225 & $2200-2800$ & Imbabura \\
\hline $\begin{array}{c}\text { INIAP } 153 \\
\text { Blanco morocho }\end{array}$ & Tardía & 250 & $2400-3000$ & Azuay y Cañar \\
\hline $\begin{array}{c}\text { INIAP } 180 \\
\text { Amarillo duro }\end{array}$ & Tardía & 260 & $2200-300$ & Varias \\
\hline $\begin{array}{c}\text { INIAP } 192 \\
\text { Blanco harinoso }\end{array}$ & Precoz & 240 & $2200-2800$ & $\begin{array}{c}\text { Pichincha } \\
\text { Tungurahua } \\
\text { Chimborazo } \\
\text { Bolívar } \\
\text { Azuay } \\
\text { Cañar }\end{array}$ \\
\hline
\end{tabular}


El maíz de polinización abierta producido en la Sierra de Ecuador se siembra en lotes pequeños de hasta una hectárea, una buena proporción de estos lotes están ubicados en suelos marginales que incluyen áreas de ladera, en muchos de ellos no se rota con otros cultivos y los suelos están expuestos a la erosión. Además, en varias zonas se siembran todavía variedades nativas no mejoradas. Todos estos factores hacen que el rendimiento de grano o choclo sea muy bajo lo que limita la capacidad adquisitiva y restringe el uso de insumos o mecanización (Rosas-Sotomayor et al., 2006). Como ilustración, en el Cuadro 3 se presentan los rendimientos generales de maíz suave obtenidos en el año 2012 en Ecuador.

Por otro lado, es interesante indicar que el maíz es parte de la agro biodiversidad en la economía de pequeños productores, especialmente en las zonas altas de la Sierra ya que ayuda a absorber los impactos del cambiante clima, particularmente en las faldas de montañas donde las temperaturas durante el día son altas, las zonas son ventosas y reciben lluvias intensas en determinadas épocas del año y sufren sequías prolongadas en otras. Los agricultores de las zonas altas de la Sierra han aprendido a intercalar cultivos con el maíz de acuerdo al piso climático donde se encuentran para reducir el riesgo, por ejemplo, granos como la quínoa (Chenopodium quinoa $\mathrm{W}$.), chocho (Lupinus mutabilis $\mathrm{S}$ ), raíces y tubérculos como la papa (Solanum tuberosum), melloco (Ullucus tuberosus C.) у oca (Oxalis tuberosa). Todos estos cultivos a más de representar una alternativa de rotación de cultivos para reducir el riesgo de monocultivo representan importantes fuentes carbohidratos, proteínas y aminoácidos (Oyarzun et al., 2013).

Cuadro 3. Rendimiento de grano seco y choclo de maíz suave en la Sierra de Ecuador en el año 2014 (INEC, 2015).

\begin{tabular}{|c|c|c|c|c|c|c|}
\hline Provincia & $\begin{array}{l}\text { Superficie } \\
\text { cosechada }\end{array}$ & Producción & $\begin{array}{c}\text { Rendimiento } \\
\text { promedio }\end{array}$ & $\begin{array}{l}\text { Superficie } \\
\text { cosechada }\end{array}$ & Producción & $\begin{array}{c}\text { Rendimiento } \\
\text { promedio }\end{array}$ \\
\hline & \multicolumn{3}{|c|}{-------------- Grano seco --------------- } & ----- C & o --------------- & \\
\hline & ha & t métricas & $\mathrm{t} \mathrm{ha}^{-1}$ & ha & $\mathrm{t}$ métricas & tha-1 \\
\hline Azuay & 15.913 & 6.409 & 0.40 & 15.750 & 3.347 & 0.21 \\
\hline Bolívar & 18.525 & 6.322 & 0.34 & 16.294 & 18.881 & 1.16 \\
\hline Cañar & 1.189 & 725 & 0.61 & 1.203 & 233 & 0.19 \\
\hline Carchi & 299 & 192 & 0.64 & 249 & 624 & 2.50 \\
\hline Cotopaxi & 15.927 & 5.408 & 0.34 & 12.614 & 3.254 & 0.26 \\
\hline Chimborazo & 4.864 & 1.691 & 0.35 & 7.668 & 9.296 & 1.21 \\
\hline Imbabura & 2.936 & 1.558 & 0.53 & 1.604 & 3.799 & 2.37 \\
\hline Loja & 4.629 & 4.28 & 0.93 & 4.615 & 4.693 & 1.02 \\
\hline Pichincha & 2.12 & 1.156 & 0.34 & 2864 & 6.410 & 2.24 \\
\hline Tungurahua & 203 & 69 & 0.82 & 5.48 & 20.563 & 3.75 \\
\hline
\end{tabular}




\section{Condiciones del cultivo de maíz suave en la Sierra ecuatoriana}

\subsection{Suelos de la Sierra ecuatoriana}

La distribución espacial de los diferentes tipos de suelos en el Ecuador depende fundamentalmente de los factores de formación, particularmente de los materiales parentales que originaron los suelos, sin embargo, esta distribución es independiente de las regiones naturales en las que está dividido el país. Desde el punto de vista de clasificación, la Sierra ecuatoriana está dividida en tres regiones: 1) Sierra Norte que recientemente ha recibido aportes de cenizas y lapilli que han contribuido a la formación de suelos derivados de ceniza volcánica clasificados como Andisoles, 2) Sierra Central que no ha recibido aportes recientes de materiales volcánicos y que se ha desarrollado de rocas metamórficas que se han transformado en una diversidad de suelos dependiendo de la altitud; en los sectores de mayor altitud se pueden encontrar Ultisoles, en las secciones medias Molisoles y Vertisoles y en la parte baja suelos poco desarrollados como Inceptisoles y Entisoles, y 3) Sierra Sur de superficies muy irregulares formadas sobre depósitos de gra- nitos y formaciones metamórficas junto a depósitos coluviales. En las Figuras 1 y 2 se presenta la distribución de los suelos de la Sierra ecuatoriana de acuerdo al material parental y la irregularidad del paisaje. En consecuencia, los suelos de la Sierra Norte (secciones norte y central de la Sierra) están dominados por alófana, imogolita y complejos de humus-Al y se caracterizan por ser suelos de coloración negra, con textura media, fertilidad media baja y ligeramente ácidos ubicados en los flancos internos y externos de las cordilleras y los nudos interiores, mientras que los valles, hoyas y cuencas están formadas por materiales coluvioaluviales de diferente granulometría y de mediana y baja fertilidad. Finalmente, la Sierra central y la sur (hacia el sur del país) han evolucionado de forma que han desarrollado una diversidad de suelos no volcánicos, generalmente arcillosos, distribuidos en forma aleatoria dominados por complejos ferrosos y arcillas de tipo 2:1 como montmorillonita y vermiculita. La fertilidad de estos suelos varía con el tipo de arcilla dominante (Moreno et al., 2016). En todos estos suelos se cultiva maíz de polinización abierta en diversas condiciones y ambientes, siempre en lotes de pequeños productores, la mayoría en las provincias de la Sierra Norte (Cuadro 3).

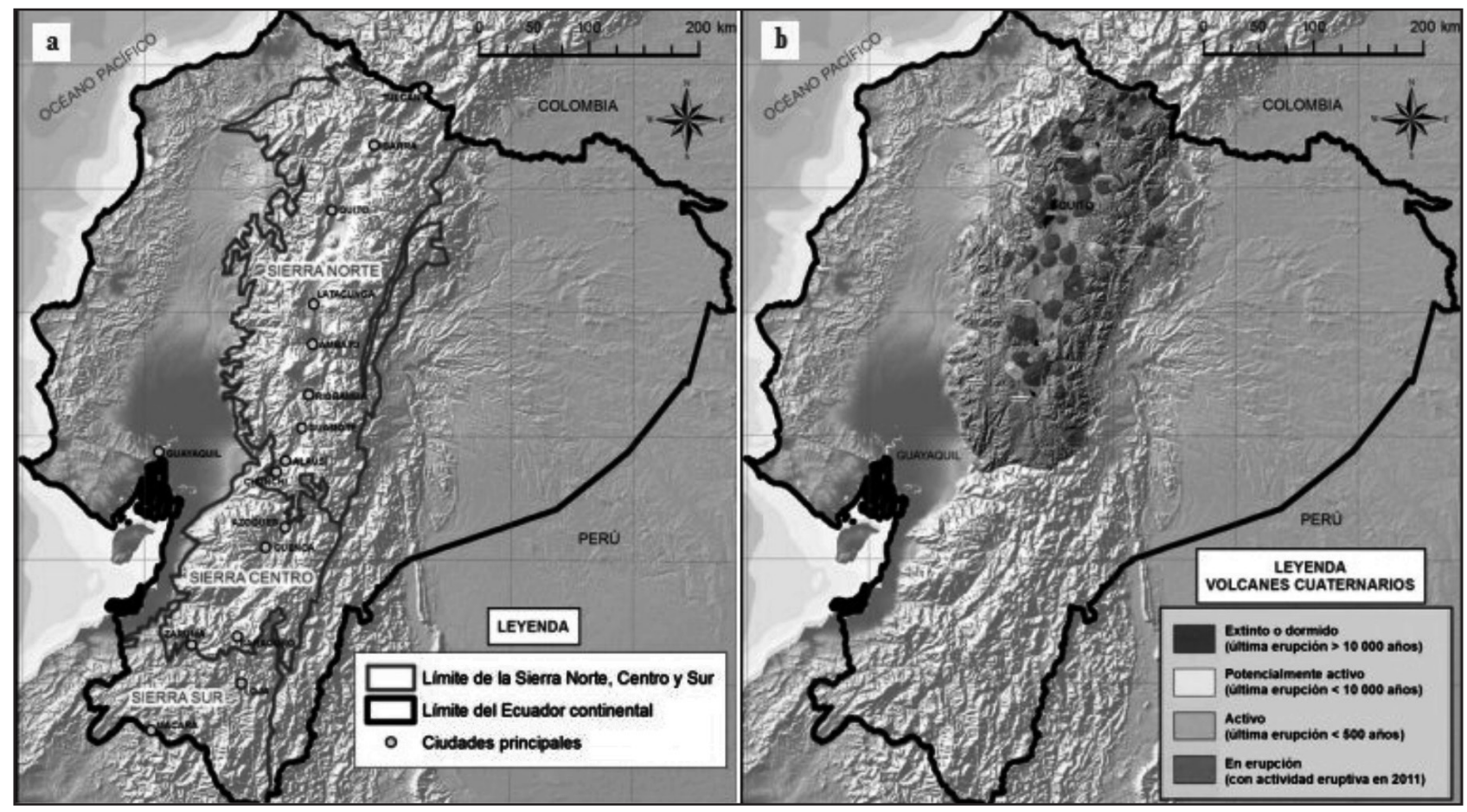

Figura 1. a) Distribución de los suelos en la Sierra ecuatoriana de acuerdo con su material parental, b) Zona de influencia volcánica que caracteriza a la Sierra Norte (Moreno et al., 2016; Winckell et al., 1997). 


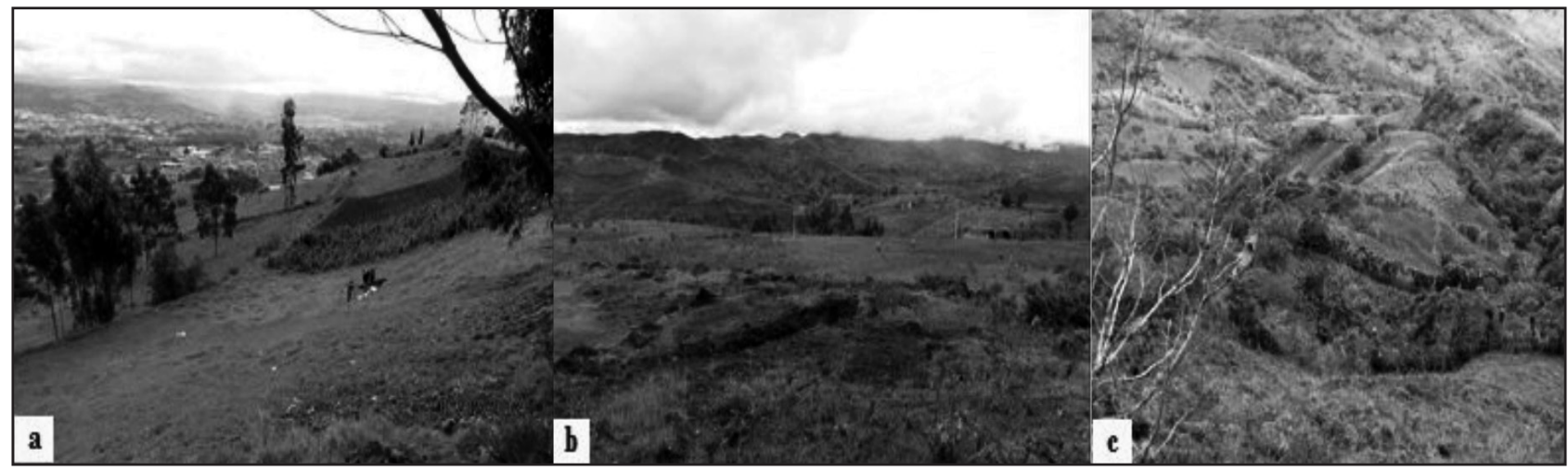

Figura 2. Áreas representativas de los suelos de la Sierra ecuatoriana, a) Chambo, Chimborazo (Sierra Norte), b) Sigsig, Azuay (Sierra Centro) y c) Olmedo, Loja (Sierra Sur) (adaptado de Moreno et al., 2016).

\subsection{Sistemas de producción de maíz de polinización abierta en la Sierra}

La época de siembra del maíz suave en la Sierra ecuatoriana varía con la del periodo de lluvias de la zona. En general, en la Sierra Norte la época de la siembra comienza en septiembre y avanza hasta mediados de enero coincidiendo con periodos de lluvia de las zonas de producción (INIAP, 2008). El ciclo del cultivo varía desde 205 hasta 270 días (Cuadro 2), pero éste depende de que si la cosecha se hace en choclo o grano seco. La distribución de la semilla en el campo determina el espacio entre plantas o densidad de siembra, condición que influencia el desarrollo vegetativo, la distribución del follaje y captación de luz por el cultivo, factores decisivos en la producción de biomasa y rendimiento de grano de acuerdo al potencial de rendimiento del cultivar en un ambiente determinado (Chim et al., 2014; Espinosa \& García, 2009).

El sistema de siembra de los maíces de polinización abierta en la Sierra es, en su mayoría, un procedimiento manual, como ocurre con las variedades liberadas por el INIAP que han sido desarrolladas para siembra en áreas de pendiente. Las distancias de siembra recomendadas para estos materiales son de $1 \mathrm{~m}$ entre hileras y $0,50 \mathrm{~m}$ entre golpes de siembra que es el sitio donde se colocan de 2 a 3 semillas, esperando establecer una densidad de siembra que en teoría debería estar entre 40.000 a 60.00 plantas ha ${ }^{-1}$ si germinan las 2 o 3 semillas sembradas, respectivamente (Peñaherrera, 2011). Sin embargo, cuando germinan las 2 ó 3 semillas las plantas resultantes compiten por supervivencia en el sitio de germinación haciendo que las plantas crezcan en forma desuniforme, es decir, una planta crece razonablemente bien, mientras que las otras se quedan pequeñas. Esto reduce significativamente el potencial de rendimiento de grano de estos materiales. Otras recomendaciones de densidad de siembra generadas por el INIAP son de $0,90 \mathrm{x}$ $0,25 \mathrm{~m}$ o $1 \times 0,20 \mathrm{~m}$ para poblaciones de alrededor de 44.000 plantas ha $^{-1}$ (INIAP, 2008). Por otro lado, esta forma de siembra también hace variable la profundidad de colocación de las semillas en el suelo. La siembra a diferentes profundidades hace que las plantas crezcan en forma poco uniforme lo que afecta el rendimiento por competencia entre plantas y alarga en cierta forma el periodo vegetativo (Omara et al., 2014).

Los niveles de rendimiento del maíz no necesariamente están ligados al nivel de sofisticación de los sistemas de producción, es decir que la siembra manual y manejo convencional de los productores de agricultura familiar tendría una buena posibilidad de rendimientos altos si el material genético utilizado está adaptado a las condiciones de clima del sitio y si los factores agronómicos como la humedad disponible, el porcentaje de germinación (población), fertilización y características agronómicas de la variedad son manejados con más cuidado (Aguiluz, 1998). Todo esto finalmente permitiría obtener rendimientos cercanos al rendimiento potencial del material genético utilizado, ya sea por peso total de grano cosechado o por el número de choclos recolectados.

\subsection{Factores que afectan la producción de maíz}

\subsubsection{Manejo del suelo y erosión}

El sistema tradicional de labores de preparación del suelo para siembra del cultivo de maíz suave utilizado por los productores en la Sierra ecuatoriana remueve el suelo para eliminar las malezas y 
preparar los surcos de siembra. El manejo continuo del suelo de la manera tradicional ha promovido cambios profundos en las propiedades físicas, químicas y bilógicas del suelo, con efectos negativos en el rendimiento de los cultivos y en el ambiente. Los argumentos para mantener prácticas de remoción del suelo para la siembra son variados. Se dice que la remoción del suelo es necesaria para controlar las malezas, permitir una mejor aireación del suelo, evitar la compactación y desarrollar un medio adecuado para el desarrollo de las raíces. Sin embargo, la constante remoción destruye los poros del suelo afectando el movimiento de agua, gases y nutrientes y además oxida la materia orgánica $(\mathrm{MO})$ y reduce los contenidos de carbono orgánico (CO). Todas estas condiciones afectan el crecimiento saludable del cultivo ya que, al contrario de lo que se piensa, se reduce la disponibilidad y el transporte del agua, aire y nutrientes, la resilencia del suelo a la degradación, compactación, erosión, sequía y otras condiciones de estrés (Craswell \& Lefroy, 2001; Kanal \& Ko1li, 1996; Weil \& Magdoff, 2004; Wingeyer et al., 2015; Winters et al., 1988). No existe en Ecuador información publicada sobre los efectos de la remoción en las propiedades del suelo, pero en el campo son evidentes las condiciones de degradación producidas por el constante movimiento de suelo para la siembra y el posterior control de malezas. En la
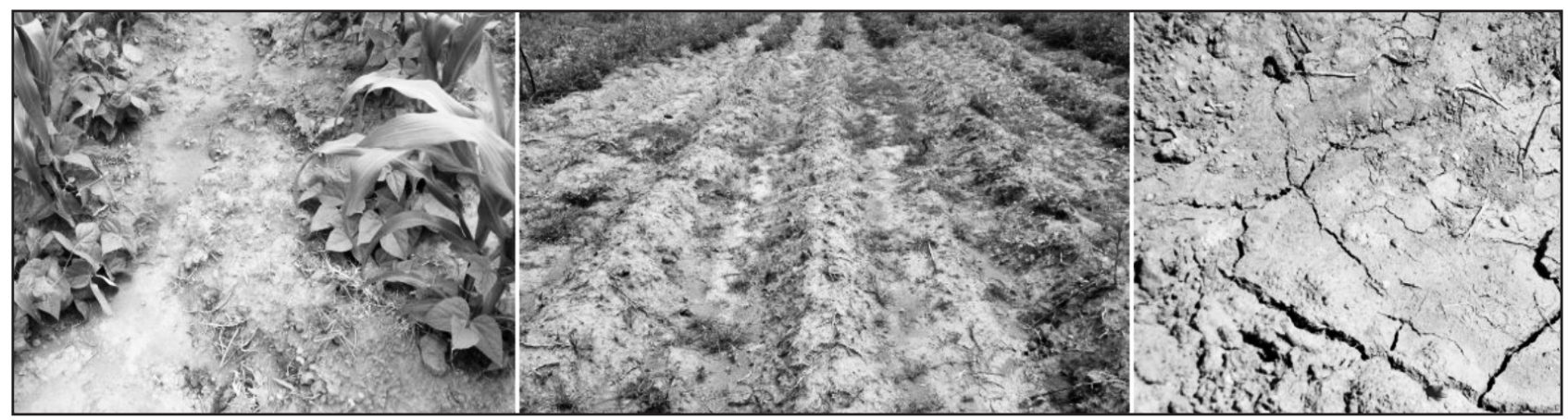

Figura 3. Efecto de la remoción constante del suelo para la siembra y el posterior control de malezas. Se observa la degradación del suelo por pérdida de estructura y contenido de materia orgánica.

Figura 3 se presentan ejemplos de degradación por constante movimiento de suelo en la Sierra Norte. El crecimiento de la población rural ecuatoriana ha obligado a los agricultores a usar tierras marginales para la producción, particularmente tierra de pendientes muy inclinadas de las laderas de la Sierra. Además, también por la presión sobre la tierra, los lotes se han ido dividiendo hasta crear una complicada red de minifundios donde la agricultura está limitada por la escasez de recursos y la mala ubicación de los lotes de producción. La división de la tierra deja en el campo lotes alargados ubicados a favor de la pendiente, condición que promueve la erosión. La poca disponibilidad de tierra para la agriculturafomenta, además, el uso intenso y la utilización de prácticas agrícolas que favorecen la pérdida del suelo. Este es el caso de la práctica de preparar el suelo en el sentido de la pendiente ya sea con bueyes o con tractor (Moreno et al., 2016). En la Figura 4 se presentan ejemplos de la acelerada erosión de los suelos de la Sierra de Ecuador.

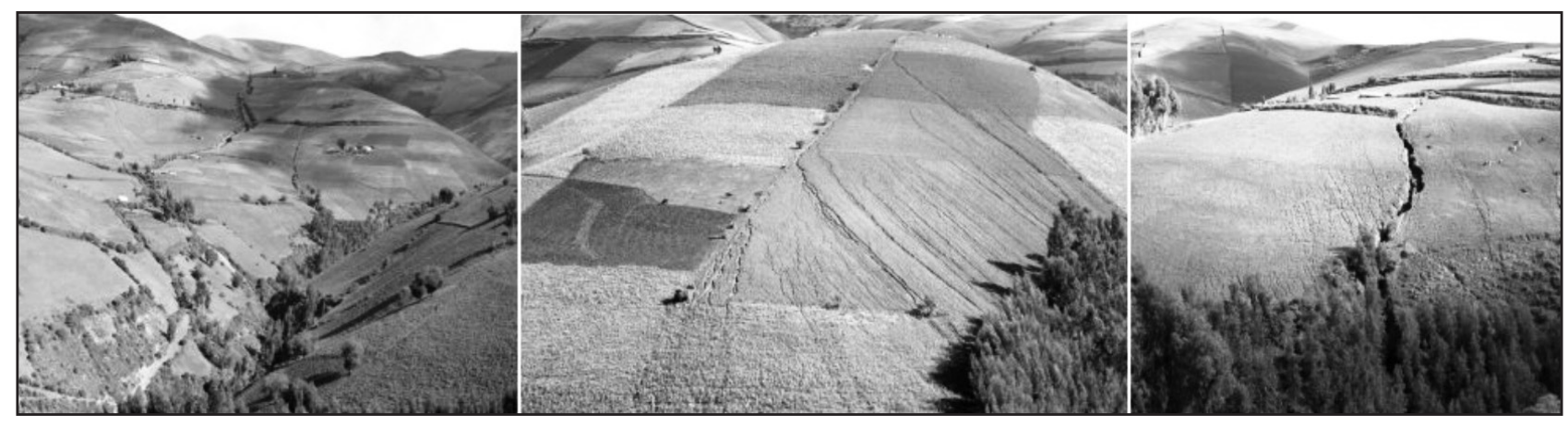

Figura 4. Acelerado proceso de erosión en de productores de agricultura familiar en la Sierra ecuatoriana. 
Mantener el suelo desnudo, sin protección en la superficie, es una de las principales causas de la erosión en estas zonas. Cuando el suelo no está cubierto con vegetación o con rastrojo, las gotas de lluvia desprenden las partículas fácilmente y provocan una acelerada erosión. Varias son las razones por las que los agricultores mantengan el suelo desnudo, una de ellas es la utilización del rastrojo como combustible o alimento para el ganado. La agricultura conducida en lotes pequeños y medianos es precaria por falta de recursos y tecnología. Esto hace que los cultivos crezcan en forma poco uniforme y que no cubran bien el suelo. Si a esto se suma la conformación de los surcos favor de la pendiente, el problema solamente se agrava (Dercon et al., 2007; Espinosa, 2014). La erosión es quizá el problema de degradación ambiental más grave del Ecuador ya que afecta a más el 50\% del suelo cultivado en la Sierra (Alvarado et al., 2011).

Sin embargo, es necesario aclarar que la erosión no es patrimonio de los pequeños productores ya que también se presenta con la misma intensidad en propiedades grandes con mal manejo. El riego ha contribuido activamente al proceso erosivo, tanto en predios pequeños como en las propiedades grandes. Paradójicamente, el riego tan necesario para la producción, termina eliminando la capa fértil del suelo, el principal sostén de la producción agrícola. Muy pocos proyectos de riego incluyen las indispensables prácticas de conservación de suelos que harían eficiente y sostenible la inversión en riego (Southgate y Whitaker, 1994; Vanacker et al., 2003).

\subsubsection{Fertilidad y fertilización de los suelos cultiva-} dos con maíz suave

Las plantas extraen del suelo los nutrientes que requieren para su crecimiento y producción, sin embargo, cuando no se devuelven al suelo los nutrientes exportados en la cosecha la fertilidad del suelo se agota rápidamente y los rendimientos se reducen significativamente. Para devolver los nutrientes al suelo se pueden utilizar fuentes minerales y fuentes orgánicas. La forma clásica de determinar las cantidades de nutrientes necesarios para mantener el rendimiento del cultivo es la utilización del análisis de suelos como herramienta de diagnóstico. Para que el análisis de suelos sea una herramienta útil es necesario calibrarlo para el tipo de suelo y para el cultivo en el cual se desea utilizarlo (Espinosa \& García, 2009). Sin embargo, en Ecuador no se ha conducido la investigación necesaria para calibrar los análisis para las variedades de maíz suave sembradas en la Sierra y esta ausencia de información complica el manejo de nutrientes en estas variedades de polinización abierta.

En el Cuadro 4 se presenta la poca información publicada sobre la absorción de nutrientes por materiales de maíz de polinización abierta que permite acercarse a una recomendación de fertilización. Esta información no es suficiente porque no toma en cuenta el aporte del suelo. Por otro lado, también aparecen en la literatura recomendaciones de fertilización basadas en el análisis de suelos como las que se presentan en el Cuadro 5 de las cuales no se conoce el trabajo de calibración.

Cuadro 4. Cantidades de macro y micronutrientes absorbidos por el cultivo de maíz de polinización abierta (Peñaherrera, 2011).

Rendimiento
Absorción de nutrientes, $\mathrm{kg} \mathrm{ha}^{-1}$

K20 C

$135 \quad 43$

58

30
En este punto es necesario reconocer que, en las circunstancias actuales, es muy complicado para el productor de agricultura familiar pueda acceder al servicio de análisis de suelos por su complejidad y la dificultad logística de recoger la muestra y enviarla al laboratorio. Es aquí donde se hace necesario innovar para encontrar herramientas que permitan que el agricultor logre manejar los nutrientes en búsqueda de alcanzar el potencial de rendimiento para el clima de sitio de siembra. 
La innovación en manejo de nutrientes deberá también tomar en cuenta la incorporación de los abonos verdes y otros abonos orgánicos. Los abonos verdes aprovechan el $\mathrm{N}_{2}$ de la atmósfera incorporado en los tejidos de las leguminosas por medio de la fijación biológica. Dependiendo de la leguminosa se pueden incorporar al suelo cantidades importantes de $\mathrm{N}$ en forma disponible para las plantas (Jen-Hshuan, 2006; van Zwieten et al., 2015). Tres t ha ${ }^{-1}$ de abono verde de vicia y avena incorporado al suelo al momento de la floración aportan 46, 14, 84 y $3 \mathrm{~kg}$ de N, $\mathrm{P}_{2} \mathrm{O}_{5}, \mathrm{~K}_{2} \mathrm{O}$ y MgO, respectivamente (Parra et al., 2014). La contribución aproximada de nutrientes de una tonelada de otros abonos orgánicos es la siguiente: gallinaza 25-50, 20, 30 y $6 \mathrm{~kg}$ de $\mathrm{N}, \mathrm{P}_{2} \mathrm{O}_{5}, \mathrm{~K}_{2} \mathrm{O}$ y $\mathrm{MgO}$, respectivamente; estiércol vacuno $20,13,20$ y $12 \mathrm{~N}, \mathrm{P}_{2} \mathrm{O}_{5}$, $\mathrm{K}_{2} \mathrm{O}$ y $\mathrm{MgO}$, respectivamente; $\mathrm{y}$, humus de lombriz 4, 5, 2 y $2 \mathrm{~kg} \mathrm{~N}, \mathrm{P}_{2} \mathrm{O}_{5}, \mathrm{~K}_{2} \mathrm{O}$ y $\mathrm{MgO}$, respectivamente.

Cuadro 5. Interpretación del análisis de suelos y recomendaciones de fertilización para el cultivo de maíz de polinización abierta (Peñaherrera, 2011).

\begin{tabular}{cccc}
\hline Niveles según el análisis & \multicolumn{2}{c}{${\text { Recomendación de nutrientes, } \mathbf{k g ~ h a}^{-1}}^{2}$} & $\mathbf{\text { P205 }}$ \\
\cline { 2 - 4 } & $\mathbf{N}$ & 80 & 60 \\
Bajo & 60 & 60 & 30 \\
Medio & 40 & 40 & 20 \\
\hline
\end{tabular}

\section{Posibles innovaciones para el cultivo de maíz en la Sierra ecuatoriana}

El manejo actual de las variedades de polinización abierta en manos de los productores de agricultura familiar lleva a cosechar rendimientos bajos de maíz seco o choclo. El rendimiento promedio de la producción de grano del año 2014 fue menor a una $\mathrm{t}$ ha $^{-1}$ (INEC, 2015) entendiéndose que el rango es más amplio y que deben haber rendimientos más altos en algunos sitios, pero de lo observado en el campo en los últimos años, la apariencia de los lotes hacía asumir que los rendimientos serían bajos (Cuadro 3). Es necesario entonces pensar en alternativas de manejo que permitan incrementar los rendimientos modificando las densidades de siembra, introduciendo prácticas de labranza que reduzcan o eliminen el movimiento del suelo y mejorando la nutrición del cultivo.

\subsection{Alternativas al manejo de la densidad de siembra}

Como norma de manejo general, los productores de maíz suave utilizan 2 a 5 semillas por golpe logrando, aparentemente, densidades de 35000 a 40000 plantas ha $^{-1}$ (Tobar, 2006). El colocar varias semillas en el mismo hoyo de siembra hace que exista competencia por recursos entre las plántulas germinadas y esto hace que una sola planta crezca bien, mientras que el crecimiento de las otras es limitado lo que reduce notablemente la real población de plantas en el campo. INIAP recomienda sembrar a $0,90 \times 0,25 \mathrm{~m}$ o 1 x $0,20 \mathrm{~m}$ utilizando 2-3 semillas por golpe para lograr poblaciones de 44.000 a 50.000 plantas ha ${ }^{-1}$ lo que permitiría alcanzar rendimientos de grano de 2,6 a 3,2 $\mathrm{tha}^{-1}$ (INIAP, 2008; Peñaherrera, 2011). Si se toma en cuenta que el rendimiento de una variedad de maíz depende de la radiación solar, la temperatura y la densidad de siembra (Evans, 1993), siendo la densidad la que controla la tasa a la cual se desarrollan las hojas bajo una particular condición de radiación solar y temperatura, es decir, controla la magnitud de fotosíntesis de las hojas, es necesario evaluar cambios en la densidad de siembra normalmente utilizada en maíz suave en la Sierra de Ecuador. 
El espaciamiento de semillas determina la distribución de las plantas en el campo, afecta la estructura de las plantas, la intercepción de la luz y la eficiencia de uso de la radiación y, en consecuencia, afecta la acumulación de biomasa y el rendimiento de grano (Chim et al., 2014; Omara et al., 2014). Con estas premisas en mente, Chim et al. (2014) iniciaron trabajos de investigación para probar el efecto de diferentes espaciamientos entre hileras y plantas para alcanzar diferentes densidades de siembra con maíz híbrido sembrado manualmente simulando lo que podrían hacer los productores cultivando áreas pequeñas de maíz híbrido en América Central. Se probaron densidades de siembra de 1,2 y 3 semillas por golpe con espaciamiento entre plantas $0,16,0,32$ y $0,48 \mathrm{~m}$ y $0,76 \mathrm{~m}$ entre hileras, lo que se traduce en poblaciones de $80.000,40.000 \mathrm{y}$ 30.000 plantas $\mathrm{ha}^{-1}$. Los mejores rendimientos se obtuvieron con espaciamientos de $0,16 \mathrm{~m}$ con una sola semilla por golpe $\left(11,3 \mathrm{t} \mathrm{ha}^{-1}\right)$, con el espaciamiento de $0,32 \mathrm{~m}$ se tuvo menor producción $\left(6,5 \mathrm{t} \mathrm{ha}^{-1}\right)$. Se observó que el rendimiento disminuye de 12 a $15 \%$ si se pone más de una semilla por golpe. En general, los mejores rendimientos se obtuvieron sembrando una semilla a una distancia de $0,16 \mathrm{~m}$ entre plantas y a 0,76 $\mathrm{m}$ entre hileras. Se pudo calcular, además, que el rendimiento se puede incrementar en $0,25 \mathrm{t} \mathrm{ha}^{-1}$ por cada $2,54 \mathrm{~cm}$ en espaciamiento.

Como se había indicado, al disminuir el espaciamiento entre plantas se logra un mejor aprovechamiento de la radiación solar y de la fertilidad del suelo, sin embargo, los efectos positivos del incremento de población llegan a estabilizarse en determinado momento para luego convertirse en un efecto negativo ya que se genera estrés por competencia entre plantas. Esta información serviría de base para diseñar experimentos que permitan conocer el potencial de rendimiento de grano de las variedades de maíz suave cultivadas en la Sierra cuando se las siembra a diferentes densidades. Por otro lado, los resultados de los experimentos con densidades demostraron que existe una relación directa entre la cantidad de plantas y el número de mazorcas obtenidas, indicando que con la distribución en el campo todas plantas tienen la oportunidad de producir mazorca. Esto es también alentador para los agricultores que producen choclo ya que el número de mazorcas en choclo fresco aumenta con las densidades, con la densidad de 80.000 plantas ha ${ }^{-1}$ se obtendrían las respectivas mazorcas haciendo más rentable la producción.

Investigación conducida en Ecuador en los últimos años reporta rendimientos de 5,2 y 7,4 t ha-1 de grano de maíz suave en las provincias de Bolívar y Pichincha, respectivamente, utilizando 2 semillas por golpe en una densidad de 50.000 plantas ha $^{-1}$ con un manejo diferente de la nutrición del cultivo y labranza cero (Alvarado et al., 2011).

\subsection{Alternativas al manejo del suelo}

El manejo convencional del suelo por parte de los productores de maíz de la Sierra ecuatoriana remueve excesivamente el suelo y promueve la degradación al destruir la estructura y oxidar la MO. Parecería que la íntima relación de la mujer u hombre de campo con la tierra haría obligatorio el proceso de movimiento del suelo para producción. Diversas son las razones esgrimidas por los productores para mover el suelo, entre otras, control de malezas, aireación del suelo, mejor condición para la germinación de las semillas, etc., sin embargo, los efectos a largo plazo del constante movimiento del suelo causan el efecto completamente contrario al buscado, es decir, incrementan la población de malezas, destruyen la agregación del suelo e impiden la circulación de aire, agua y nutrientes y reducen drásticamente el contenido de MO. Todas estas condiciones reducen la fertilidad del suelo y promueven la erosión.

De hecho, la erosión es uno de los problemas que enfrentan los productores de agricultura familiar. La principal consecuencia de la erosión es la pérdida de suelo productivo, el recurso más valioso para la agricultura. La erosión arrastra las capas superficiales del perfil del suelo que son las que tienen mayor contenido de MO y nutrientes. Las nuevas capas de suelo expuestas a la superficie tienen baja fertilidad y malas condiciones físicas. En consecuencia, los cultivos sembrados en suelos erosionados tienen poco vigor y baja productividad. A medida que avanza la erosión y se pierde más suelo, la situación se hace más precaria hasta que finalmente aflora el subsuelo, dejando una matriz de suelo completamente improductiva. Estas condiciones son comunes en muchas áreas de la Sierra ecuatoriana y solo traen pobreza, lo que lleva finalmente al abandono del campo (Vanacker et al., 2003). Los suelos erosionados son menos fértiles y producen cultivos menos vigorosos que cubren menos el suelo, dejan menor cantidad de residuos y pierden paulatinamente la MO. Este efecto lo ven los agricultores en el campo y es común el comentario de que la parcela antes producía más y mejores cosechas (Moreno et al., 2016).

En el pasado, el problema de erosión se minimizaba porque los suelos eran profundos y las zanjas y cárcavas provocadas por la erosión eran cubiertas con un pase de tractor o bueyes y, aparentemente, nada había ocurrido. Esto simplemente continuaba reduciendo la profundidad del suelo hasta que aparecía el subsuelo. Este ha sido un problema de muchos años que ha degradado completamente los suelos en muchos sitios de la Sierra. 
Los métodos para controlar la erosión no son desconocidos ni complicados de adoptar. Sin embargo, muchos productores los ven como una molestia porque obligan a manejar los lotes en forma diferente a la tradicional, que, aparentemente, es más rápida y simple. Los objetivos de la adopción de estas prácticas de conservación deben buscar proteger la superficie del suelo y reducir el volumen y la velocidad del agua de escorrentía sobre el campo (Espinosa, 2014).

Quizá la práctica de manejo que mejor controla la erosión en el campo es la siembra directa (SD) que se basa en la siembra de los cultivos sin remover el suelo dejando sobre el campo todos los residuos de la cosecha anterior (Lal et al., 2007; Rivera, 2003). Este es un sistema de manejo del suelo que se practica en áreas extensas en América del Norte y en las planicies de Argentina y Brasil en América del Sur con el uso intenso de maquinaria agrícola y que ha demostrado que se puede producir rendimientos altos en forma sostenida sin la necesidad de remover el suelo (Wingeyer et al., 2015). A pesar del éxito de la SD en extensas zonas del mundo, esta forma de manejo no ha sido adoptada en las zonas de cultivo en manos de pequeños productores América Central y América del Sur. La SD es ideal para el cultivo de maíz de polinización abierta en la Sierra de Ecuador y se ajustaría fácilmente al manejo del cultivo. Han sido pocos lo intentos por probar el sistema con pequeños productores porque aparentemente es muy complicado que sea adoptado por la agricultura familiar.
Experimentos conducidos por el INIAP en las provincias de Bolívar y Pichincha no solamente demostraron que la SD es factible sino que también es posible obtener rendimientos de maíz de polinización abierta considerablemente más altos que los obtenidos con labranza convencional (5,2 y 7,4 tha ${ }^{-1}$ de grano con SD en Bolívar y Pichincha, respectivamente) (Alvarado et al., 2011). Existe una amplia gama de posibilidades de investigación en SD con maíz y otros cultivos de la Sierra que permiten documentar el efecto de esta práctica en las propiedades físicas, químicas y biológicas del suelo, el control de erosión, el secuestro de carbono y los rendimientos.

Se ha desarrollado equipo para SD adaptado a las condiciones de pequeños productores que se ha probado en diferentes países, particularmente Brasil. Estos equipos funcionan bien, pero su costo alto limita su uso por los productores de agricultura familiar. En la Figura 5 se observa el uso de un equipo de siembra directa y el resultado de la siembra de maíz de polinización abierta en la Sierra de Ecuador. Normalmente, los pequeños agricultores siembran maíz con un espeque, es decir, un madero alargado con punta afilada en uno de los extremos. La siembra se puede hacer razonablemente bien, se puede colocar las densidades esperadas y el artefacto es simple y fácil de usar. En la Figura 6 se presenta el resultado de SD de maíz con espeque en lotes de pequeños productores.

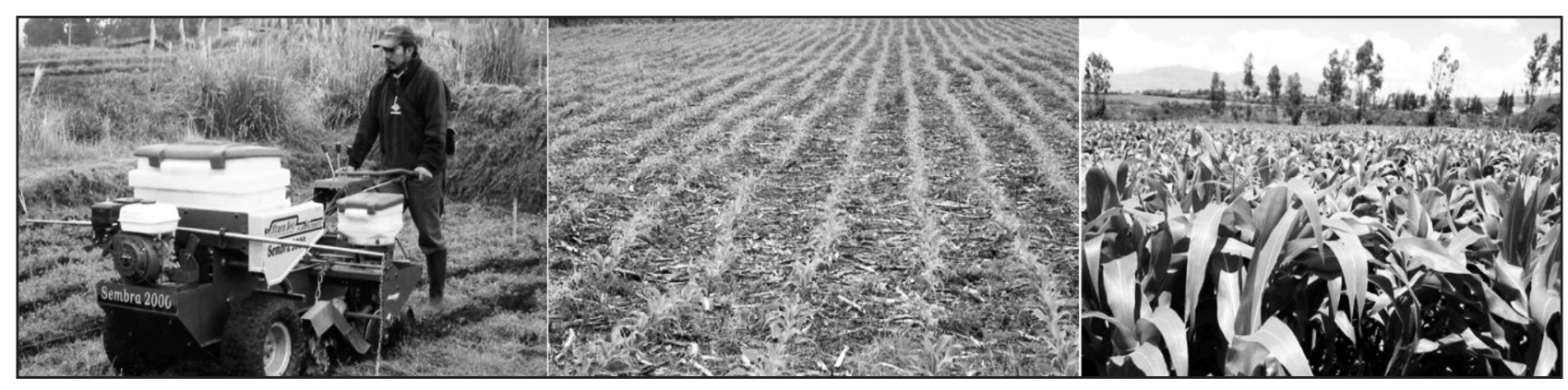

Figura 5. Siembra de maíz de polinización abierta usando el equipo Sembra 2000 en lotes de pequeños productores en Riobamba, Ecuador.

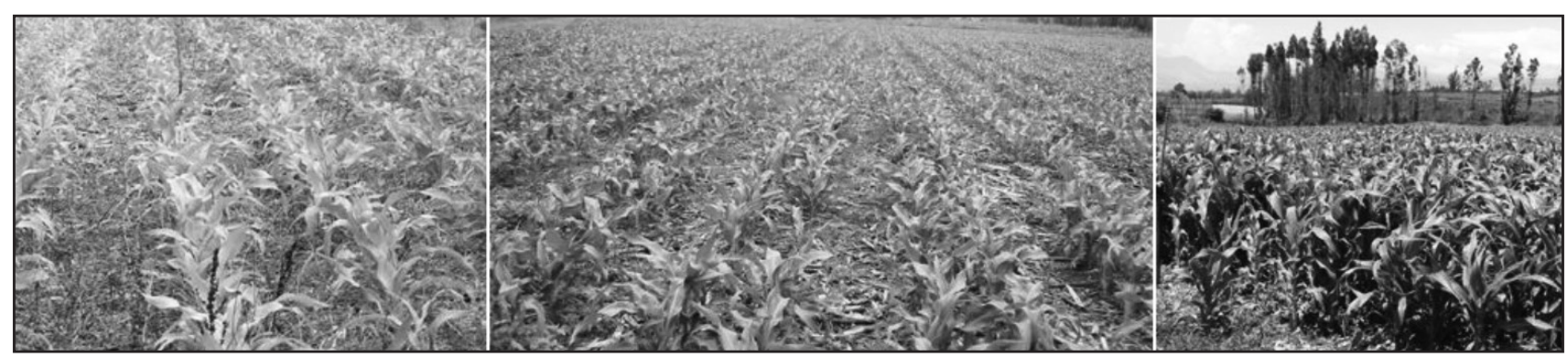

Figura 6. Siembra de maíz de polinización abierta utilizando el tradicional espeque en lotes de pequeños productores en Checa, Pichincha, Ecuador. 
Recientemente, la universidad de Oklahoma condujo una investigación para innovar el espeque utilizado para sembrar maíz por pequeños productores de América Central. Producto de esta investigación se diseñó el denominado sembrador de mano (hand planter) que es un dispositivo que deposita una sola semilla por golpe, asegura uniformidad de la profundidad de siembra y de la colocación del fertilizante. Los rendimientos obtenidos fueron mayores de $9,0 \mathrm{tha}^{-1}$ de grano de maíz híbrido con poblaciones que variaron de 60.000 a 90.000 plantas ha ${ }^{-1}$. El dispositivo tiene un diseño sencillo y accesible para los agricultores, está estructurado por un eje giratorio y tiene una punta hueca de metal diseñada para penetrar el suelo y depositar únicamente una semilla (Omara et al., 2014). La uniformidad en la profundidad de siembra es un factor importante para asegurar la población, ya que la siembra demasiado profunda afecta la uniformidad de la población, genera competencia entre plantas y afecta directamente al rendimiento de grano (Bragachini et al., 2012). En la Figura 7 se presenta el uso y diseño del sembrador de mano desarrollado por la universidad de Oklahoma. Este dipositivo debe probarse con los productores de maíz de polinización abierta de la sierra de Ecuador.

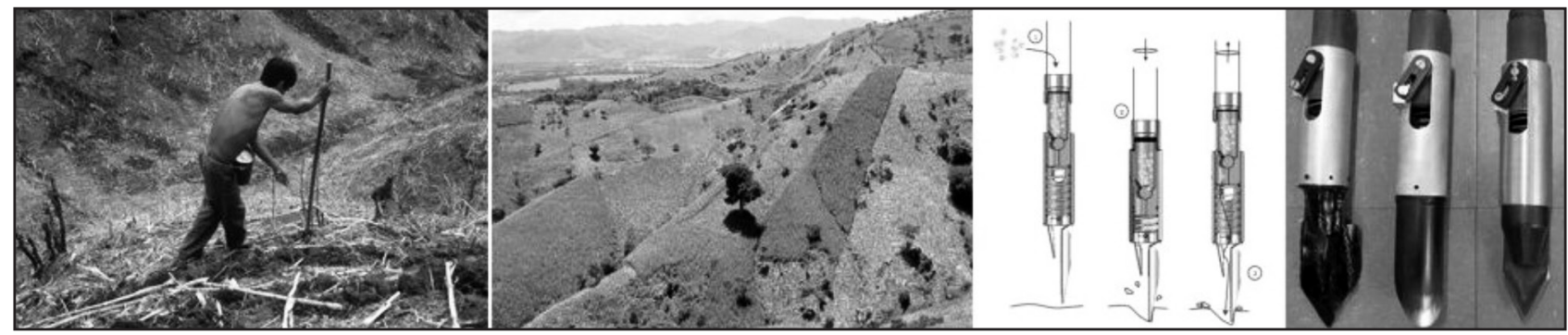

Figura 7. Uso y diseño del sembrador de mano (hand planter) desarrollado por la universidad de Oklahoma ((Raun \& Taylor, 2014).

\section{Conclusiones}

Las tierras de los productores de agricultura familiar en la Sierra ecuatoriana están, en su mayoría, ubicadas en suelos con pendientes propensas a erosión. Además de la erosión, el constante movimiento para las labores de siembra y control de malezas ha desgastado el suelo con el consecuente deterioro de las propiedades físicas, químicas y biológicas junto con la pérdida constante de carbono orgánico.

La producción de maíz suave de polinización abierta para grano seco y choclo es una opción interesante dentro de los de cultivos que los pequeños agricultores utilizan para su sustento y para la generación de ingresos a su economía. Sin embargo, las técnicas tradicionales para producción de maíz como la preparación del suelo y la siembra no logran que se desarrolle el cultivo y produzca el potencial que el ambiente permite. El tradicional método de siembra que ubica de 3 a 4 semillas por golpe, a una distancia de $1 \mathrm{~m}$ entre hileras y 0,50 $\mathrm{m}$ entre golpes, no permite alcanzar una población de plantas que logre utilizar la radiación solar en forma eficiente. Además, solo una planta de las que geminan en el sitio de siembra logra establecerse bien y las otras quedan pequeñas por competencia. Todo esto reduce significativamente la posibilidad de alcanzar un rendimiento adecuado.
Se ha demostrado que se puede lograr poblaciones altas y uniformes de maíz de polinización abierta en el campo utilizando cuidadosamente el espeque y colocando una sola semilla por sitio a distanciamientos que pueden variar de 0,7 a $0,8 \mathrm{~m}$ entre hileras y de 0,18 a $0,25 \mathrm{~m}$ entre plantas para lograr densidades de siembra superiores a 60.000 plantas ha $^{-1}$. De esta forma, las plantas crecen uniformemente, pueden utilizar la luz de manera eficiente y pueden acumular rendimientos de grano adecuados. Si el objetivo es producir choclo, esta forma de siembra asegura una mazorca de adecuado tamaño por planta que permite producir buen choclo para el mercado. Si bien existe equipo para siembra de granos en lotes de pequeños productores, estos son caros y difíciles de conseguir y de mantener. El uso cuidadoso del espeque permite realizar un trabajo adecuado con respecto a la población de plantas en el campo. Al respecto, trabajos realizados con pequeños productores de maíz en América Central ha permitido desarrollar un sembrador manual que es un espeque mejorado que permite colocar una sola semilla a una profundidad uniforme para lograr de esta forma establecer poblaciones igualmente espaciadas que utilicen eficientemente la radiación solar. Se debe explorar las posibilidades del uso de este sembrador con los pequeños productores de maíz de la Sierra Ecuatoriana.

Por otro lado, es necesario reducir o eliminar el movimiento del suelo para tareas de siembra y control 
de malezas por medio de la SD o cero labranza. Con la SD no se remueve el suelo, se dejan que se acumulen los residuos de cosechas anteriores en la superficie y se coloca la semilla en el suelo sin moverlo utilizando el espeque. Esta es quizá la práctica de manejo de suelo que tendrá más impacto a largo plazo en la producción ya que permite que los suelos se recuperen al mejorarse sus propiedades físicas, químicas y biológicas al lograr acumular nuevamente carbono orgánico en el suelo.

\section{Referencias}

Aguiluz, A. (1998). Evaluación de híbridos de maíz (Zea mays L.) de grano blanco y amarillo en ambientes de Centroamérica, Panamá y el Caribe en 1996. Agronomía Mesoamericana, 9, 28-37.

Alvarado, S., Jaramillo, R., Valverde, F. \& Parra, R. (2011). Manejo de nutrientes por sitio especifico en el cultivo de maiz bajo labranza de conservación para la provincia de Bolívar. INIAP-IPNI, Quito, Ecuador.

Berry, A. \& North, L. (2011). Los beneficios de Ia pequeña propiedad en el campo. Consultado el 20 de Marzo 2011, de http://www.rebelion.org/noticias/2011/10/138180.pdf.

Bragachini, M., Méndez, A., Scaramuzza, F., Vélez, J. \& Villarroel, D. (2012). Impacto de la velocidady la profundidad de siembra sobre uniformidad en la emergencia y distribución de plantas en maíz. Congreso de Valor Agregado en Origen. AACS, Córdoba, Argentina.

Brassel, F., Zapatta, A. \& Ruiz, P. (2008). La Estructura agraria en el Ecuador: una aproximación a su problemática y tendencias. In F. Brassel, S. Herrera and M. Laforge, editors, Reforma Agraria en el Ecuador: viejos temas nuevos argumentos. SIPAE, Quito, Ecuador. p. 17-32.

Carrión, D. \& Herrera, S. (2012). Ecuador rural del Siglo XXI: Soberanía alimentaria, inversión pública y política agraria. Instituto de Estudios Ecuatorianos, Quito, Ecuador.

Chim, B.K., Omara, P., Macnack, N., Mullock, J., Dhital, S. \& Raun, W. (2014). Effect of seed distribution and population on maize (Zea mays L.) grain yield. International Journal of Agriculture, 2014, 1-8.

Craswell, E. \& Lefroy, R. (2001). The role and function of organic matter in tropical soils. Nutrient Cycling in Agroecosystems, 61, 7-18.
La utilización de técnicas que mejoren la calidad del suelo, como la siembra directa, y que incrementen la densidad del cultivo distribuyendo las plantas uniformemente en el campo, logran incrementos sustanciales de producción en grano y choclo que contribuirían positivamente a mejorar los resultados económicos de las estrategias de producción de la agricultura familiar.

Dercon, G., Govers, G., Poesen, P., Sánchez, H., Rombaut, R., Vandenbroeck, G., Loaiza, J. \& Deckers, J. (2007). Animal-powered tillage erosion assessment in the southern Andes region of Ecuador. Geomorphology, 87, 4-15.

Espinosa, J. (2014). La erosión en Ecuador, un problema sin resolver. Siembra, 2, 56-70.

Espinosa, J. \& García, J. (2009). Herramientas para mejorar la eficiencia de uso de nutrientes en maíz. En J. Espinosa \& F. García (eds), Memorias del Simposio "Uso eficiente de Nutrientes" presentado por el IPNI en el XVIII Congreso Latinoamericano de la Ciencia del Suelo. International Plant Nutrition Institute (IPNI), Costa Rica. p. 49-56.

Evans, L.T. (1993). Crop evolution, adaptation, and yield. Cambridge Univesity Press, Cambridge, UK.

Gondard, P. \& Mazurek, H. (2001). Treinta años de reforma agraria y colonización en el Ecuador (19641994). Revista Estudios de Geografia. Dinámicas Territoriales, 10. CEN, CGE, IRD, PUCE, Quito.

INEC. (2015). Encuesta de Superficie y Producción Agropecuaria Continua. Instituto Nacional de Estadística y Censos, Quito, Ecuador.

INIAP. (2008). Informe anual de actividades del Programa de Maíz. Programa de Maíz - Estación Experimental Santa Catalina, Quito, Ecuador.

Jen-Hshuan, C. (2006). The combined use of chemical and organic fertilizers and/or biofertilizer for crop growth and soil fertility. International workshop on sustained management of the soil-rhizosphere system for efficient crop production and fertilizer use. Land Development Department Bangkok, Bangkok, Thailand.

Kanal, A. \& Kolli, R. (1996). Influence of cropping on the content, composition and dynamics of organic 
residue in the soil of the plough layer. Biology and Fertility of Soils, 23, 153-160.

Lal, R., Reicosky, D. \& Hanson, J. (2007). Evolution of the plow over 10,000 years and the rationale for notill farming. Soil and Tillage Research, 93(1), 1-12.

Márquez Sánchez, F. (2008). De las variedades criollas de maíz (zea mays) a los híbridos transgénicos: I. Recolección de germoplasma y variedades mejoradas. Agricultura, Sociedad y Desarrollo, 5(2), 151-166.

Moreno, J., Yerovi, F., Herrera, M., Sánchez, D. \& Espinosa, J. (2016). Soils from the ecuadorian highlands. En: J. Espinosa, J. Moreno and G. Bernal, (eds), Sois of Ecuador. Springer, Netherlands.

Omara, P., Koller, A., Lam, E., Macnack, N., Ringer, J., Mullock, J., Dhital, S. \& Raun, W. (2014). Hand planter for maize (Zea mays L) in the develping world. Journal of Plant Nutrition, 368, 12-24.

Oyarzun, P.J., Borja, R.M., Sherwood, S. \& Parra, V. (2013). Making sense of agrobiodiversity, diet, and intensification of smallholder family farming in the highland Andes of Ecuador. Ecology of Food and Nutrition, 52(6), 515-541.

Pandey, S., Diallo, A., Islam, T. \& Deutsch, J. (1986). Progress from selection in eight tropical maize populations using international testing. Crop science, 26(5), 879-884.

Parra, R., Quishpe, J., Valverde, F. \& Alvarado, S. (2014). Los abonos verdes. INIAP, Quito, Ecuador.

Peñaherrera, D. (2011). Módulo IV: Manejo integrado del cultivo de maíz suave. Módulos de capacitación para capacitadores. INIAP, Quito, Ecuador. p. 52.

Raun, B. \& Taylor, R. (2014). OSU green seeder planter. Consultado el 15 de Diciembre 2015, de http://nue. okstate.edu/Hand Planter.htm.

Rivera, J. (2003). La labranza de los suelos en el tropico: ¿necesidad o costumbre?. Curso nacional: Hacia un nuevo enfoque de producción y manejo de los recursos forrajeros tropicales en la empresa ganadera. CORPOICA, Manizales, Colombia.

Rosas-Sotomayor, J.C., Guzmán, O.G. \& Torres, J.J. (2006). Mejoramiento de maíces criollos de Honduras mediante la aplicación de metodologías de fitomejoramiento participativo. Agronomía Mesoamericana, 17(3), 383-392.
Southgate, D. \& Whitaker, M. (1994). Economic Progress and the Environment. One Developing Country's Policy Crisis. Oxford University Press, New York.

Tobar, M. (2006). Mejora genética de la variedad de maiz Chillo (Zea mays L) por selección basal visual estratificada moderna (segundo ciclo). Tesis de Ingeniero Agrónomo, Escuela Politénica del Ejército, Quito, Ecuador.

van Zwieten, L., Rose, T., Herridge, D., Kimber, S., Rust, J., Cowie, A. \& Morris, S. (2015). Enhanced biological $\mathrm{N}_{2}$ fixation and yield of faba bean (Vicia faba L.) in an acid soil following biochar addition: dissection of causal mechanisms. Plant and Soil, 395, 7-20.

Vanacker, V., Govers, G., Barros, S., Poesen, J. \& Deckers, J. (2003). The effect of short-term socioeconomic and demographic change on landuse dynamics and its corresponding geomorphic response with relation to water erosion in a tropical mountainous catchment, Ecuador. Landscape Ecology, 18(1), 1-15.

Vásquez, L. \& Saltos, N. (2000). Ecuador: su realidad. Fundación de Investigación y Promoción Social José Peralta, Quito, Ecuador.

Weil, R. \& Magdoff, F. (2004). Significance of soil organic matter to soil quality and health. En: F. Magdoff and R. Weil, (eds), Organic Matter in Sustainable Agriculture. CRC Press, Boca Ratón, USA.

Winckell, A., Zebrowski, C. \& Sourdat, M. (1997). Los paisajes naturales del Ecuador. Centro Ecuatoriano de Investigación Geográfica (CEDIG) IPGH (Sección Ecuador) - IRD (Francia) - IGM, Quito, Ecuador.

Wingeyer, A., Amado, T., Pérez-Bidegain, M., Studdert, G., Perdomo, C., Garcia, F. \& Karlen, D. (2015). Soil quality impacts of current South American agricultural practices. Sustainability, 7, 2213-2242.

Winters, P., Espinosa, P. \& Crissman, C. (1988). Manejo de los recursos en los andes ecuatorianos. Ediciones Abya-Yala, Quito, Ecuador.

Yanez, C., Zambrano, J., Caicedo, M., Sanchez, H. \& Heredia, J. (2003). Catálogo de germoplasma de recursos genéticos de maíces de altura Ecuatorianos. Programa de Maíz, EESC-INIAP, Quito, Ecuador. p. 10. 